\title{
Perbandingan Tes Balke Dan Tes Jalan Rockport Dalam Pengukuran $\mathrm{VO}_{2} \mathrm{Max}$
}

\author{
Hermanto \\ Agung Robianto \\ Fakultas Ilmu Olahraga Universitas Negeri Jakarta \\ hermanto@unj.ac.id \\ agungrobianto@unj.ac.id
}

\begin{abstract}
ABSTRAK
Tes Balke Dan Tes Jalan Rockport merupakan tes yang sering digunakan untuk mengukur VO2max oleh banyak orang dengan berbagai latar belakang olahraga. Telah dilakukan penelitian deskriptif komparatif dengan subjek penelitian 16 orang laki-laki dengan teknik Purposive Sampling. Hasil penelitian menunjukkan bahwa dari hasil uji t ditemukan terdapat perbedaan nilai VO2max yang dihasilkan oleh Tes Balke Dan Tes Jalan Rockport $(44,88 \pm 3.90,46$ vs $54,36 \pm 4,94)$. Simpulan penelitian menunjukkan terdapat nilai VO2max yang dihasilkan oleh Tes Balke Dan Tes Jalan Rockport pada subjek penelitian (dengan $\mathrm{P}$ value sebesar $0,000<\alpha=0.05)$.
\end{abstract}

\section{Kata Kunci: VO2max, Tes Balke, Tes Rockport}

\begin{abstract}
The Balke Test and the Rockport Road Test are tests that are often used to measure VO2max by many people with various sports backgrounds. Comparative descriptive research has been conducted with 16 male research subjects using the purposive sampling technique. The results showed that from the t test results it was found that there were differences in VO2max values produced by the Balke Test and the Rockport Road Test (44.88 \pm 3.90 .46 vs. $54.36 \pm$ 4.94). The conclusions of the study showed that there was VO2max value produced by the Balke Test and the Rockport Road Test on the research subjects (with a P value of $0,000<\alpha=0.05$ ).
\end{abstract}

\section{Keywords: VO2max, Balke Test, Rockport Test}

\section{PENDAHULUAN}

Kebugaran fisik merupakan suatu kondisi yang multidimensi, yaitu terdiri dari beberapa komponen. Gambaran kebugaran fisik seseorang dapat diperoleh melalui pengukuran pada komponen atau interaksi antara komponen-komponen tersebut (Rowland, 1996). Komponen dasar dari kebugaran fisik adalah daya tahan kardiorespiratori, dimana ambilan oksigen maksimal atau VO2max menjadi standar emas untuk menilainya (Kenney, et.al, 1995).

Ambilan oksigen maksimal atau $\mathrm{VO} 2 \mathrm{max}$ adalah yang paling sering digunakan sebagai indeks dari kebugaran aerobik atau daya tahan kardiorespiratori (Fernhall B et.al, 1990). VO2max merupakan volume oksigen maksimal yang dapat dikonsumsi seseorang dalam hitungan satu menit dan biasanya di relevansikan dengan massa tubuh. Karenanya, unit ukuran $\mathrm{VO} 2 \max$ adalah $\mathrm{ml} / \mathrm{kg} / \mathrm{menit}$.

Faktor fisiologi yang mempengaruhi VO2max adalah kualitas distem kardiorespiratori dalam mengirimkan oksigen yang dibutuhkan oleh otot dan kemampuan otot tersebut dalam mengekstrak dan menggunakan oksigen yang telah dikirimkan (Rowell et.al, 1996). Dalam melakukan uji kebugaran aerobik terbagi menjadi dua cara, yaitu metode langsung mengunakan tes pengukuran laboratorium dan metode tidak langsung 
atau tes lapangan. Metode langsung dilakukan dengan mengukur kapasitas aerobik atau VO2max secara langsung. Metode langsung dilakukan di laboratorium dengan menggunakan spirometer yang terkomputasi sehingga dinilai memiliki hasil yang paling objektif (Astrand, et.al, 2003). Metode tes pengukuran di laboratorium yang paling umum digunakan untuk mengukur VO2max adalah dengan cara memberikan beban kerja menggunakan sepeda statik ergometer atau treadmill, dan secara progresif beban kerja tersebut dinaikan hingga terjadi kelelahan. Selama diberikan beban kerja, konsumsi oksigen diukur secara terus menerus hingga tercapai nilai maksimalnya. Tes seperti ini membutuhkan peralatan laboratorium yang mutakhir dan tenaga fisiologis khusus (Cooper, 1970). Oleh karena itu jika ingin mengetahui dan mengukur VO2max secara langsung harus dilakukan di laboratorium olahraga atau kesehatan dengan biaya yang mahal.

Pengukuran VO2max dengan metode langsung di laboratorium cukup mahal karena harus melakukan analisis gas yang menggunakan alat laboratorium. Oleh karena itu, berbagai tes lapangan untuk mengukur VO2max dirancang untuk mengevaluasi kebugaran aerobik dengan memberikan beban kerja yang dapat diukur, contohnya berlari dengan jarak tertentu (Cooper, 1968), berlari dengan durasi waktu tertentu (Balke, 1963), melakukan lari bolak-balik dengan peningkatan kecepatan disetiap menitnya (Ramsbottom, et.all, 1988), dan berjalan dengan jarak tertentu (Kilne, at.al, 1987). Selain dapat dilakukan dengan sarana dan perlengkapan yang sederhana, keuntungan dari tes lapangan dapat dilakukan oleh subjek dengan jumlah yang besar dan dilakukan secara simultan tapi tes-tes tersebut menimbulkan potensi resiko kesehatan. Selanjutnya kelemahan dari tes-tes tersebut adalah subjek membutuhkan motivasi yang tinggi dalam menyelesaikan tes agar diperoleh hasil yang benar-benar merepresentasikan usaha yang maksimal (Anderson G.S, at.al, 1992).

Asupan maksimal oksigen (VO2max) merupakan jumlah oksigen yang dihirup, ditransportasikan, dan digunakan pada tingkat sel (Plowman dan Smith, 2011). VO2max dapat didefinisikan pula sebagai jumlah oksigen yang diinspirasi dikurangi dengan jumlah oksigen yang diekspirasi (Plowman dan Smith, 2011). VO2max disebut juga sebagai kapasitas maksimal untuk mengonsumsi oksigen oleh tubuh selama proses pengerahan tenaga maksimal, disebut juga sebagai kekuatan aerobik, asupan oksigen maksimal, dan kapasitas daya tahan kardiorespiratori (Nieman, 2011).

VO2max dinyatakan dalam milliliter (ml) dari konsumsi oksigen per kilogram $(\mathrm{kg})$ dari berat badan per menit (menit) (ml.kg-1.min-1) (Nieman, 2011). Berdasarkan satuan yang digunakan maka VO2max dapat didefinisikan sebagai jumlah oksigen maksimal yang digunakan oleh tubuh per menitnya untuk melakukan aktivitas fisik (Hoeger dan Hoeger, 2011). Nilai VO2max tergantung pada tiga fungsi penting tubuh yaitu (1) system pernapasan, (2) system kardiovaskular, dan (3) system musculoskeletal (Nieman, 2011).

Sistem pernapasan menentukan jumlah oksigen yang dapat diserap oleh paru-paru dan ditransportasikan melalui darah. Sistem kardiovaskular memiliki peran dalam memompakan dan mendistribusikan oksigen dalam darah ke tubuh. Sistem musculoskeletal bertugas mengkonversi karbohidrat dan lemak yang tersedia menjadi adenosine triphosphate (ATP) untuk konstraksi otot dan produksi panas (ACSM, 2010 dalam Nieman, 2011). Secara laboratorium, beberapa kriteria digunakan untuk menentukan pencapaian nilai VO2max yaitu konsumsi oksigen selama menit terakhir tes latihan bertingkat, respiratory exchange ratio (RER) atau rasio volume karbondioksida terhadap volume konsumsi oksigen, denyut nadi, dan level laktat dalam darah (Howley, Basset, dan Welch, 1995; Duncan, Howley, dan Johnson, 1997 dalam Nieman, 2011).

\section{Pengukuran VO2 Max}

Pengukuran VO2max merupakan pengukuran kebugaran aerobik. VO2max dapat diukur melalui dua cara yaitu pengukuran menggunakan metode tes laboratorium dan metode tes lapangan. 
Pengukuran VO2max menggunakan metode tes laboratorium merupakan metode paling akurat untuk mengukur kapasitas aerobik perorangan, tetapi untuk melakukan pengukuran tersebut terbilang mahal, membutuhkan banyak waktu, membutuhkan motivasi tinggi dari responden, dan sulit digunakan untuk mengukur subjek dalam jumlah besar (Kline, et al, 1987).

Pengukuran Kapasitas VO2 Max secara eksperimental dari kajian fisiologi seringkali digunakan tiga metode test yang sudah distandardkan. Eksperimen dilakukan dengan menggunakan alat treadmill dimana treadmill akan memberikan beban pada otot bagian bawah tubuh, dan membebankan pada tumpuan kaki untuk mempertahankan posisi tubuh karena berdiri dan kemiringan treadmill akan membuat beban beban tersendiri bagi tubuh sehingga dapat dikatakan bahwa test menggunakan treadmill lebih lengkap namun kelemahannya adalah tidak terlalu membebani punggung dan lengan.

1. Astrand (2003) mengatakan bahwa : syarat dari pengukuran VO2 max astrand adalah sebagai berikut :

a. Exercise harus melibatkan kelompok otot yang besar

b. Tingkat kerja (work rate) harus dapat dihitung dan dapat direproduksi ulang

c. Kondisi tes harus sedemikian hingga agar dapat dibandingkan dan dapat

d. diulang

e. Tes harus dapat ditoleransi oleh semua individu

f. Kemampuan (skill) untuk melakukan aktivitas eksperimen harus seseragam mungkin dalam populasi yang diujikan.

2. Protokol treadmill yang dilakukan adalah menggunakan protokol maximal test. Metode maksimal mengharuskan subjek untuk mengerahkan seluruh kemampuannya untuk mencapai konsumsi oksigen maksimumnya. Pengukuran metode tes lapangan adalah suatu metode pengukuran VO2max melalui metode estimasi (prediction). Pengukuran metode tes lapangan telah dikembangkan ke berbagai bentuk tes seperti tes kebugaran lapangan, tes naik turun tangga, uji laboratorium submaksimal, uji laboratorium maksimal
(Nieman, 2011). Disebut sebagai tes lapangan karena pengukurannya dilaksanakan di lapangan. Tes ini membutuhkan usaha responden untuk mendapatkan skor kebugaran aerobik yang tinggi. Jenis tes kebugaran lapangan ini seperti berjalan, berjalan-berlari, berlari, bersepeda, berenang, dan sebagainya (ACSM, 2008).

3. Tes Balke 15 Menit Telah terbukti secara luas bahwa VO2max adalah salah satu faktor utama yang mempengaruhi performa pada olahraga, walaupun faktor yang lainnya juga mempunyai pengaruh yang signifikan (Lehmann et al, 1983; Sjodin dan Svedenhag, 1985). VO2max merefleksikan kemampuan sistem kardiovaskular untuk mengirimkan oksigen ke otot-otot yang sedang bekerja, sehingga nilai VO2max juga mencerminkan tingkat kebugaran aerobik dan kebugaran kardiovaskular (Rowell et al, 1964). Tes Balke 15 menit merupakan sebuah tes lapangan yang dibuat untuk mengukur $\mathrm{VO} 2 \mathrm{max}$ secara tidak langsung. Tes ini dilakukan dengan cara berlari dengan kecepatan yang optimal selama 15 menit di lintasan lari, selanjutnya jarak yang ditempuh selama 15 menit tersebut di catat dan dikonversikan menjadi satuan VO2max menggunakan formula Balke (Balke B, 1963).

4. Tes Jalan Rockport 1600 Meter Saat ini Kementerian Kesehatan telah mensosialisasikan tes pengukuran VO2max menggunakan metode tes jalan Rockport 1600 Meter dengan pertimbangan bahwa tes tersebut mudah, murah, masal dan efisien (Departemen Kesehatan RI, 2005). Tes ini dilakukan dengan cara berjalan sejauh 1600 meter yang dilakukan di lintasan atletik, adapun hasil yang diukur dalam tes jalan rockport 1600 Meter adalah waktu tempuh dan denyut nadi rata-rata yang selanjutnya hasil tersebut dikonversi menjadi satuan VO2max menggunakan formula Rockport (Kilne, 1987)

\section{METODE PENELITIAN}

Desain penelitian ini adalah survey analitik yang menggunakan studi korelasional untuk mencari hubungan dari kedua variabel tersebut. Subjek pada 
penelitian ini dipilih dengan menggunakan metode purposive sampling dengan kriteria sebagai berikut:

1. Kelompok usia 17-25 tahun.

2. Sehat dan bersedia menjadi sampel penelitian.

3. 3. Tidak memiliki riwayat penyakit berat seperti Jantung, Hipertensi, Diabetes, dan lainnya.

4. Tidak pernah dirawat di rumah sakit dalam jangka waktu $\geq 2$ minggu dalam 1 bulan terakhir.

Jumlah sampel yang digunakan adalah sebanyak 15 orang dengan tingkat aktifitas fisik sedang dan berat, kuesioner IPAQ digunakan untuk mendapatkan sampel dengan kriteria tingkat aktifitas fisik sedang dan berat.

\section{HASIL PENELITIAN}

Karakteristik Fisik Fisiologis Subjek Penelitian

Tabel 1. Karakteristik fisik fisiologis subjek peneletian berupa usia (tahun), berat badan $(\mathrm{kg})$, tinggi badan $(\mathrm{cm})$ dan indeks massa tubuh $(\mathrm{kg} / \mathrm{m} 2)$

\begin{tabular}{|c|c|c|c|}
\hline Karakter Fisik & $\mathbf{n}$ & $x$ & $\pm S d$ \\
\hline Usia (tahun) & 1 & 19,9 & $\pm 1,2$ \\
\hline Tinggi Badan $(\mathrm{cm})$ & $\begin{array}{l}1 \\
6\end{array}$ & $\begin{array}{l}169 \\
06\end{array}$ & $\begin{array}{l}4,5 \\
\pm\end{array}$ \\
\hline Berat Badan (kg) & $\begin{array}{l}1 \\
6\end{array}$ & $\begin{array}{l}66,9 \\
4\end{array}$ & $\begin{array}{l}11 \\
\pm \quad 34\end{array}$ \\
\hline $\begin{array}{l}\text { Indeks Massa Tubuh } \\
(\mathrm{kg} / \mathrm{m} 2)\end{array}$ & $\begin{array}{l}1 \\
6 \\
\end{array}$ & 23,8 & $\begin{array}{ll} & 3,5 \\
\pm & 7 \\
\end{array}$ \\
\hline
\end{tabular}

Uji Normalitas dan Homogenitas Data Penelitian

Hasil pengukuran VO2max dengan metode tes lari balke 15 menit dan tes jalan rockport 1600 meter seperti tercantum pada lampiran. Selanjutnya hasil pengukuran tersebut dilakukan uji Normalitas menggunakan metode uji Kolmogorov-smirnov $(p>0,05)$ dan uji homogenitas varian menggunakan metode uji Levene's test $(p>0,05)$, hasilnya menunjukkan data nilai VO2max yang dihasilkan pada metode tes lari balke 15 menit dan tes jalan rockport 1600 meter berdistribusi normal dan homogen seperti tercantum pada gambar dibawah ini;

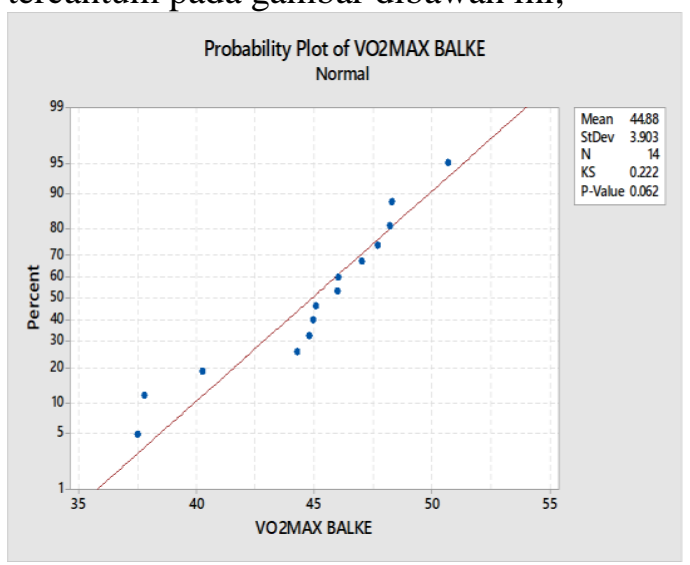

Gambar 1 Hasil Uji Normalitas Nilai

VO2max yang dihasilkan pada tes lari Balke 15 menit

Dari hasil uji distribusi data normal menggunakan software Minitab 17.0 dengan metode uji kologorov-smirnov, menyatakan bahwa data Nilai VO2max yang dihasilkan pada tes lari Balke 15 menit memiliki nilai $\mathrm{P}=0.062$ karena nilai $\mathrm{P}>\alpha=0.05$ maka data berdistribusi normal.

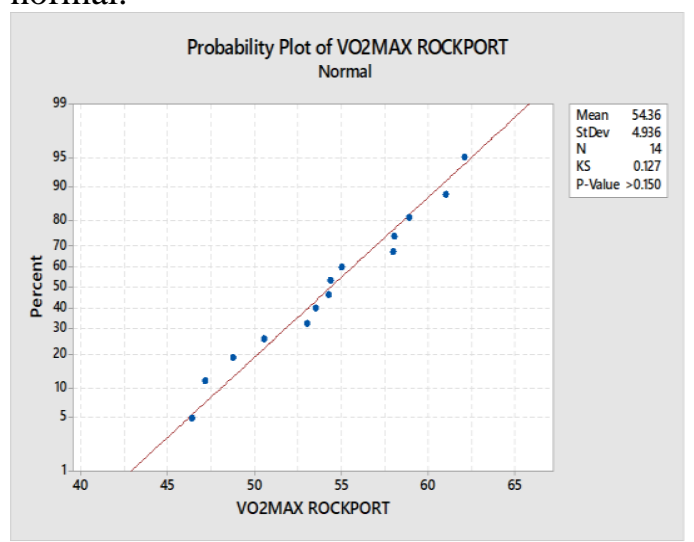

Gambar 2 Hasil Uji Normalitas Nilai

VO2max yang dihasilkan pada tes jalan rockport 1600 meter

Sedangkan hasil uji distribusi data normal menggunakan software Minitab17.0 metode uji kologorov-smirnov, menyatakan bahwa data Nilai VO2max yang dihasilkan pada tes jalan rockport 1600 meter memiliki nilai $\mathrm{p}=0.150$ karena nilai $\mathrm{p}>\alpha=$ 0.05 maka data berdistribusi normal. 


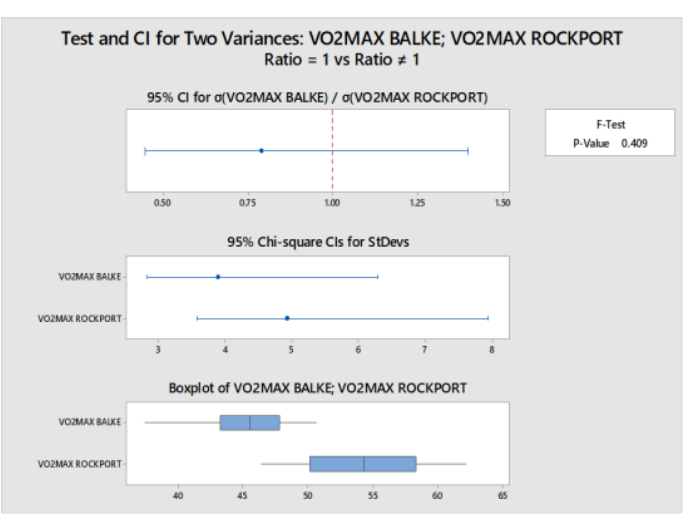

Gambar 3 Hasil Uji Homogenitas Hasil Penelitian

Dari hasil uji homogenitas data menggunakan software Minitab 17.0 metode uji $\mathrm{F}$ menghasilakan nilai $\mathrm{P}=0.409$ $>\alpha=0.05$ maka data Nilai VO2max yang dihasilkan pada tes jalan rockport 1600 meter memiliki variansi sama/homogen.

3. Perbandingan Tes Balke Dan Tes Jalan Rockport Dalam Pengukuran VO2max

Hasil pengukuran nilai VO2max dengan metode tes lari balke 15 menit dan tes jalan rockport 1600 meter pada lampiran. Dari hasil uji t ditemukan nilai VO2max yang dihasil pada tes lari balke 15 menit dan tes jalan rockport 1600 meter $(44,88 \pm 3.90,46$ vs $54,36 \pm 4,94)$.

Tabel 2. Perbedaan nilai VO2max yang dihasilkan pada tes lari balke 15 menit dan tes jalan rockport 1600 meter

\begin{tabular}{ccc}
\hline \multirow{2}{*}{ Variabel } & \multicolumn{2}{c}{ Nilai Vo2max } \\
\cline { 2 - 3 } & $\mathrm{x}$ & $\mathrm{sd}$ \\
\hline Metode CPET & 44.88 & 3.9 \\
\hline Metode MSFT & 54.36 & 4.94 \\
\hline $\mathrm{df}$ & \multicolumn{2}{c}{26} \\
\hline T value & \multicolumn{2}{c}{-5.64} \\
\hline $\mathrm{P}$ & \multicolumn{2}{c}{0.000} \\
\hline
\end{tabular}

Perbandingan nilai VO2max yang dihasilkan pada tes lari balke 15 menit dan tes rockport 1600 meter, perhitungan perbandingan menggunakan software Minitab 17.0 metode uji $\mathrm{T}$ dengan nilai $\alpha=$ 0.05 .

Hasilnya nilai t hitung sebesar 5.64 pada derajat kebebasan (df) 26 dengan $\mathrm{P}$ value sebesar $0,000>\alpha=0.05$ sehingga jawaban hipotesis adalah terdapat perbedaan Mean yang bermakna antara nilai VO2max yang dihasilkan pada tes lari balke 15 menit dan tes rockport 1600 meter.

\section{Pembahasan}

Hasil penelitian pada tabel 4.4 menunjukkan bahwa terdapat perbedaan yang bermakna pada nilai VO2max yang dihasilkan pada tes lari balke 15 menit dan tes rockport 1600 meter. Hal ini ditunjukkan oleh hasil uji t nilai VO2max yang dihasilkan pada tes lari balke 15 menit dan tes rockport 1600 meter $(44,88 \pm 3.90,46$ vs 54,36 $\pm 4,94$ ) dengan $\mathrm{P}$ value sebesar $0,000<\alpha=0.05$, sehingga dapat disimpulkan bahwa terdapat perbedaan Mean yang bermakna antara nilai VO2max yang dihasilkan pada tes lari balke 15 menit dan tes rockport 1600 meter.

Dari hasil penelitian terdapat temuan bahwa ada perbedaan yang berarti pada nilai VO2max Tes lari balke 15 menit dan Tes jalan rockport 1600 meter. Hal tersebut dimungkinkan terjadi karena kedua tes ini dilakukan dengan aktifitas yang berbeda. Dimana tes rockport 1600 meter dengan aktifitas berjalan tidak mampu memaksimalkan kinerja aerobik sehingga nilai VO2max yang dihasilkan lebih tinggi dibanding dengan tes Balke 15 menit yang menggunakan aktifitas berlari yang mampu memaksimalkan kinerja aerobik.

\section{KESIMPULAN}

Simpulan penelitian menunjukkan terdapat perbedaan yang berarti antara nilai VO2max yang dihasilkan oleh Tes Balke Dan Tes Jalan Rockport pada subjek penelitian $(44,88 \pm 3.90,46$ vs $54,36 \pm 4,94)$ dengan $\mathrm{P}$ value sebesar 0,000 $<\alpha=0.05)$.

\section{SARAN}

1. Untuk saran perbaikan penelitan dengan topik yang sama, hendaknya juga dilakukan pengukuran pada parameter fisiologis seperti denyut jantung dan kadar asam laktat sehingga dapat meningkatkan kualitas hasil temuan. 
1. Selain pengukuran parameter fisioolgis, hendaknya juga dilakukan penelitian dengan topik yang sama namun dengan subjek kelompok usia yang lebih beragam dan tingkat aktifitas fisik yang berbeda-beda.

\section{DAFTAR PUSTAKA}

Anderson GS. A comparison of predictive tests of aerobic capacity. Can J Sports Sci;17: 304-8 (1992)

Astrand PO, Rodahl K. Textbook of Work Physiology: Physiological Bases of Exercise. 4th ed. Champaign, Ill: Human Kinetics Inc (2003)

Balke B. A simple field test for the assessment of physical fitness. Civil Aeromedical Research Institute Report, 63-18. Oklahoma City: Federal Aviation Agency (1963)

British Association of Sports Science. (Sports Physiology Section) Position Statement on the Physiological Assessment of the Elite Competitor, Second Edition (1988)

Burger, S.C. et al. Assessment of the 2.4 $\mathrm{km}$ run as a predictor of aerobic capacity. S Afr Med J. 15 (78), p. 327-329. (1990)
Cooper KH. A means of assessing maximum oxygen intake. JAMVA; 203: 135-38. (1968)

Cooper, K. H., The New Aerobics. Bantam Books Inc., New York (1970)

Fernhall B, Millar AL, Tymeson GT. Maximal exercise testing of mentally retarded adolescents and adults: reliability study. Arch Phys Med Rehabil ;71:1065-1068 (1990)

Horwill F. Obsession for Running - A Lifetime in Athletics. London: Colin Davies Printers, (1991)

Kenney, WL., editor. ACSM's Guidelines for Exercise Testing and Prescription. Baltimore (MD): American College of Sports Medicine; p. 73 (1995)Kilne, G. et al. Estimation of $\mathrm{VO} 2$ max from a one mile track walk, gender, age and body weight. Med Sci. Sports Exerc., 19, p. 253-259 (1987)

Ramsbottom R, Brewer J, Williams C. A progressive shuttle run test to estimate maximal oxygen uptake. $\mathrm{Br} 1$ Sports Med; 22: 14144. (1988)

Rowell, L. B., Taylor, H. L. and Wang, Y., "Limitations to prediction of maximal oxygen intake". Journal of Applied Physiology 19 (5): 919927

(1964 